International Journal of Linguistics, Literature and Culture
Available online at https://sloap.org/journals/index.php/ijllc/
Vol. 6, No. 1, January 2020, pages: 70-78
ISSN: 2455-8028
https://doi.org/10.21744/ijllc.v6n1.845

\title{
Code-Switching as a Translanguaging to Transfer Cross-Cultural Understanding in English Classroom: Teachers' Perception
}

Kadek Adyatna Wedananta ${ }^{\text {a }}$

Article history:

Submitted: 09 November 2019

Revised: 18 December 2019

Accepted: 22 January 2020

\section{Keywords:}

code-switching; cross-cultural understanding;

English classroom;

teachers' perception;

translanguaging;

\begin{abstract}
This study was identifying code-switching as a translanguaging to transfer cross-cultural understanding in the classroom. This study used observation to one classroom and unstructured questionnaire to seven English lecturers/ teachers qualitatively. Most of the participants used Inter-sentential Code Switching, which describes a switch of language at sentence boundary or between the sentences. They used the code-switching consciously for some factors, such as the desire to convey meaning effectively, the desire to make the communication more inclusive, the desire to improve students' comprehension, the desire to convey the meaning contextually, the desire to emphasize the meaning or comprehension, and the desire to help EFL learners by bilingual. Moreover, the most important thing is they believe that code-switching affects English classroom positively in transferring crossculture understanding, such as code-switching eases students to understand more to the cultural topics, code-switching can improve students' comprehension on conceptual knowledge such as cultural activities, attitude and belief, and code-switching is useful for EFL learners where they can match their English with local wisdom. Finally, the code-switching here is not used to differentiate between two languages or the replacement but it is used to mediate each other especially when transferring cross-cultural understanding, to express or emphasize the substance, and to improve students' comprehension in cultural activities, attitude, and belief.
\end{abstract}

International journal of linguistics, literature and culture @ 2020. This is an open access article under the CC BY-NC-ND license (https://creativecommons.org/licenses/by-nc-nd/4.0/).

Corresponding author:

Kadek Adyatna Wedananta,

Undiknas University, Denpasar Indonesia.

Email address: adyatnawedananta@undiknas.ac.id

${ }^{\mathrm{a}}$ Undiknas University, Denpasar Indonesia 


\section{Introduction}

Nowadays the students should have the skill due to other languages as additional training for them to compete in the job market. Besides that, in this globalization era, there are a number of people who, personally, in aesthetic, in academic and in economic reasons, are being multilingual. Hence, there were many reasons to find out something about a second language (L2), English. Furthermore, there are respective ways of teaching the L2 in the schoolroom. Teaching L2 in the schoolroom that is unitary of the popular trend is teaching L2 trough L2 as what most people believed for over the years in any country which learn the L2 in this case English.

Nevertheless, the evidence that is pictured aside from the outcome of the students who learned the L2 through L2 is below the expectation. It is even hard for the students to master the L2. It is plainly expressed in the upshot of the tests where the L2 scores always low for most of the pupils. Garcia (2009) states that translanguaging is the routine performed by bilinguals of accessing different linguistic features or various models of what are described as autonomous languages, in parliamentary procedure to maximize communicative potential. Translanguaging is the method for utilizing the primary language of the understudies to help the understudies learning the second language in the schoolroom. Translanguaging will streamline the understudies' authority in L2 since the procedure of instructive action and learning is viable.

Code-switching is a kind of translanguaging because it is the alternative use by bilinguals of two or more languages in the same conversation" (Milroy \& Muysken, 1995). For Gumperz (1982), code-switching can be defined as the juxtaposition within the same speech or exchange of passages of speech belonging to different grammatical systems or subsystems. Established along with the explanation above, the researcher was interested in identifying code-switching as a translanguaging in the classroom. Interestingly, it might help to connect to the cultural understanding where everyone should understand the meaning of the languages based on their own language mastered.

\section{Research Questions}

1) What kinds of code-switching occurs in English Classroom?

2) What factors influence the emersion of code-switching in the English Classroom?

3) How code-switching affects English Classroom in transferring Cross-Cultural Understanding?

\section{Objectives of the study}

1) To identify what kinds of code-switching occurs in the English Classroom

2) To identify factors that influence code-switching strategy in the English Classroom

3) To know how code-switching affects English Classroom in transferring Cross-Cultural Understanding

\section{Literature Review \\ Code-Switching}

Troike (2006), stated, in the study of an SLA and language teaching, the concept of communicative competence became a basic tenet in the study of sociolinguistics and is presently taken by many specialists. It involves knowing not simply the vocabulary, phonology, grammar, and alternative views of linguistic structure, however additionally once to talk, what to mention, to whom, and a way to say it befittingly in any given scenario. In fact, the term communicative competence was first coined by Hymes (1967), to which he referred as the aspect of individuals ${ }^{\text {ee }}$ competence enabling them to communicate and interpret the message and negotiate the meaning interpersonally within a specific setting. In other words, communicative competence is associated with the knowledge that allows a person to communicate functionally and interactively (Brown, 2000). Thus, "communicative competence can be explicated in terms of three components competencies, grammatical competence, sociolinguistic competence and strategic competence (Dornyei \& Thurell, 1991). Thus, Duranti (2001) claims that "Communicative competence was also intended to advance the work of different codes and modes of communicating within and across situationsll. To conclude, communicative competence is, of course, the ability to communicate and it concerns both spoken and written language in addition to all the four language skills (Oxford, 1990). Accordingly, Troike (2006), states that -multilingual speakers' total communicative competence differs from that of a monolingual in including knowledge of formulae for the appropriate selection of terminology and for switching between languages, given a particular societal context and communicative design.

Wedananta, K. A. (2020). Code-switching as a translanguaging to transfer cross-cultural understanding in English classroom: teachers' perception. International Journal of Linguistics, Literature and Culture, 6(1), 70-78. 
Strategic competence is the mastery of strategic skill in a language. It requires the power to communicate information to a listener and correctly read the obtained data. Thus it is the mastery of communication strategies employed to deal with problems that may happen during the operation of transmitting any message or data. Therefore, strategic competence has to make out with the power to get one es meaning across to particular listeners successfully (Torane \&Yule, 1989; Maba, 2017).

Celce-Murcia et al. (1995), consider strategic competence as knowledge of communication strategies and how to apply them. It includes strategies relevant to language learning, language processing, and language production. Then, it is knowledge of verbal and non-verbal communication strategies that enhance the efficiency of communication where necessary, and enable the learner to overcome difficulties when communication breakdowns occur CelceMurcia et al., 1995).

Communication Strategies are employed to achieve communicative goals, especially when the person goes into a problem of missing knowledge. They result from the person 's staying in the conversation, and therefore, provide the opportunity for further learning as well as further communication (Oxford, 1996). Dornyei Classification of Com Ss. Traditional Conceptualizations (Adopted from Dornyei, 1995).

Avoidance or Reduction Strategies:

1) Message abandonment: leaving a message unfinished as a result of language difficulties

2) Topic avoidance: avoiding topic areas or ideas that create language difficulties. The achievement of Compensatory Strategies

3) Circumlocution: describing or exemplifying the target object/ action

4) Approximation: using another term that expresses that means of the target lexical item as closely as potential

5) Use of all-purpose words: extending a general, empty lexical item to contexts wherever specific words area unit lacking.

6) Word-coinage: creating a non existing L2 word based on a supposed rule.

7) Use of nonlinguistic means: mime, gesture, facial expression, or sound imitation.

8) Literal translation: translating virtually a lexical item, an idiom, a compound word or structure from L1 to L2.

9) Foreignizing: using an L1 word by adjusting it to L2 phonologically and/or morphologically.

10)Code-switching: using an L1 word with L1 pronunciation or an L3 word with L3 pronunciation in L2

11)Appeal for help: turning to the conversation partner for help either directly or indirectly. Stalling or Timegaining Strategies

12)Use of fillers/hesitation devices: using filling words or gambits to fill pauses and to achieve time to suppose.

For many decades, code-switching has been examined mistreatment numerous linguistic approaches inside the frameworks of linguistics, cognitive psychology, and grammatical studies all of that have to place bigger stress either on the descriptive or on the theoretical prospects of the development. At this point, Milroy \& Muyskens (1995), stated, it appears to be additional and additional proof that Code Switching could be a language universal within the behavior of multilingual speakers or to use a shorthand definition of Code-Switching applying many languages or language varieties within the course of a speech relies on speech internal mechanisms evident in many social settings everywhere the globe (Shafi et al., 2020).

Thus, code-switching is ,the alternative use by bilinguals of two or more languages in the same conversation ${ }^{\text {ce }}$ (Milroy \& Muysken, 1995). For Gumperz (1982), code-switching can be set as the juxtaposition within the same speech or exchange of passages of speech belonging to different grammatical systems or subsystems. Also, Milroy and Muysken view code-switching as a significant aspect in the bilingual speech that is linguistically natural. It is not a result of a lack of competence on the part of the speaker in one or both of the languages. In other words, CS is the alternating role of languages by bilingual speakers. It does not indicate incompetence on the role of the speakers in whatever language (Milroy \& Muysken, 1995).

According to Poplack (1980) and Romaine (2000), CS is classified as follow:

a) Tag Switching: it includes the introduction of tags or exclamation in one language into the conviction which is otherwise in another language (Romaine, 1995 as cited in Nguyen, 2014). This case of switching refers to the addition of tags that are constituent could be moved freely and well-performed by speakers. Poplack (1980), tag switching involves the interjections, fillers, tags, and idiomatic expressions, all of which can be produced in L2 with only minimal knowledge of the grammar of that speech. This intends that this type, when made, does not violate the rule of the grammar of the language L2.

b) Inter-sentential Code Switching: the second type of code-switching used to describe a switch of language at sentence boundary or between the sentences. Resulting from that one sentence or part of the sentence that can 
occur in one language and the following part in another language (Romaine, 1995 as cited in Nguyen, 2014). In inter-sentential switch, Romaine means the alternation at clause or sentence level where the conviction or the clause is in one language or another. It occurs between speech turns where the utterance must conform to the rules of both languages. Then, following Poplacks ${ }^{\text {ee }}$ point of view, inter-sentential code-switching requires a higher level of proficiency in both languages than tag switching (Poplack, 1980).

c) Intra-sentential Code Switching: this third type of code-switching refers to the switch within a sentence. Precisely, it is the switch to another language occurring within clause boundary or even within the word boundary. It is assumed to require the greatest fluency in both languages. Thus, here, Romaine (2000) as cited in Nguyen (2014) claims that intrasentential code-switching bears the greatest danger of violating syntactic rules and is so often avoided even by fluent bilinguals. In other words, this case is regarded as the most syntactically risky because only bilinguals with high fluency in both languages can apply this type without violating either language ${ }^{e e}$ s rule.

\section{Translanguaging}

Garcia (2009), conveys that translanguaging is the routine performed by bilinguals of accessing different linguistic features or various models of what are described as autonomous languages, in parliamentary procedure to maximize communicative potential. It is the means of employing the first language of the students to help the students learning the second language in the classroom. It optimizes the students' mastery in L2 since the operation of educational activity and learning is viable.

\section{Cross-cultural understanding of language learning}

The understanding of cross-culture plays an important role in interacting with people from different countries. Language and culture cannot be isolated from each other. Therefore, as learners learn a language, they should at the same time study the country's culture and the people from where the language originates in order to avoid miscommunication and confusion. Cross-cultural understanding simply refers to people's inherent ability to recognize, perceive, and respond correctly to people, incidences, or circumstances open to confusion due to cultural differences (Yulianti, 2015).

\section{Previous study}

The work came from NiemaHamad Al Haiti \& Ammar A. Al Abdely (2016). The present work is interested in analyzing the English language Iraqi doctor's use in conventional settings, basically to identify the types of codeswitching found. This will be performed via content analysis of data collected through tape recordings and direct reflections. The work also points to identify doctors' perceptions of the level of English they have and whether their current linguistic situation requires improvement. Outcomes indicate that Iraqi doctors use intra-sentential codeswitching additional often than the two different sorts, although it desires additional information within the L2. Results additionally counsel that Iraqi doctors use English for communicative functions. Doctors feel that English needs additional improvement.

\section{Materials and Methods}

This study used the unstructured questionnaire to answer research questions and objectives qualitatively. There were seven questions for English teachers/lecturers. The questions are about their prior knowledge about code-switching, their experiences using code-switching, factors influencing the use of code-switching, the influence of codeswitching for English classrooms in transferring cross-culture understanding, the potential of code-switching for English classroom, code-switching for students and other examples of code-switching.

\section{Data Analysis}

An interactive data analysis model (Huberman, 1987), will be applied to analyze collected data qualitatively, which consists of three activities, such as, data reduction, data display, and conclusion (see Fig. 3.2). The three activities in

Wedananta, K. A. (2020). Code-switching as a translanguaging to transfer cross-cultural understanding in English classroom: teachers' perception. International Journal of Linguistics, Literature and Culture, 6(1), 70-78. 
interactive data analysis can be stated as follow: Data Reduction, data reduction means that the raw data gathered are selected, focused, and simplified based on the aims of the research. This action will be performed in order to separate the used and the unused data so that the researcher can focus on the data used; Data Display, data display is organizing the data so that it can be used for drawing a conclusion or verifying. This action will be made out by transforming the reduced data into tables or written arrangements; in Conclusion, a researcher will draw the conclusion from the available data. If the researcher perceives that, the data are not enough to make a conclusion, the data collection process will be conducted to capture more data, and those data will be rechecked by doing data reduction and data presentation. This activity is continued until the researcher finds that the conclusion that is made already answers the research questions.

\title{
3 Results and Discussions
}

\author{
Findings
}

Table 1

Examples of code-switching

\begin{tabular}{|c|c|c|c|c|}
\hline \multirow[b]{2}{*}{ No. } & \multirow[b]{2}{*}{ Examples of Code-Switching } & \multicolumn{3}{|c|}{ Classification of Code-Switching } \\
\hline & & Tag Switching & $\begin{array}{l}\text { Inter-sentential } \\
\text { Code Switching }\end{array}$ & $\begin{array}{l}\text { Intra-sentential } \\
\text { Code Switching }\end{array}$ \\
\hline 1 & However saya akan. & - & - & $\mathrm{V}$ \\
\hline 2 & Keep on learning. Kamu pasti bisa. & - & V & - \\
\hline 3 & $\begin{array}{l}\text { The brain is an organ that serves as the center of } \\
\text { the nervous system. Otak adalah pusat sistem } \\
\text { saraf. }\end{array}$ & - & V & - \\
\hline 4 & $\begin{array}{l}\text { Kids, have you read or heard the balinese } \\
\text { famous fabel? Di bali rage meduwe cerita siap } \\
\text { selem. }\end{array}$ & - & V & - \\
\hline 5 & Good morning student. Om Swastyastu. & - & $\mathrm{V}$ & - \\
\hline 6 & $\begin{array}{l}\text { Small talk is an informal type of discourse that } \\
\text { does not cover any functional topics of } \\
\text { conversation or any transactions that need to be } \\
\text { addressed. Kalau dalam Bahasa Indonesia kita } \\
\text { sebut sebagai basa - basi. }\end{array}$ & - & $\mathrm{V}$ & - \\
\hline 7 & See you next week. Om shanti shanti shanti Om. & - & $\mathrm{V}$ & - \\
\hline 8 & Please tell about the botol briefly & - & - & $\mathrm{V}$ \\
\hline
\end{tabular}

Seven participants filled the unstructured questionnaire. Most of them stated that they use Inter-sentential Code Switching, which is the second type of code-switching used to describe a switch of language at sentence boundary or between the sentences. Interestingly, most of the participants answered that they know what code-switching is even though they did not tell more about its types. They may be familiar with the term "code-switching" because they were graduated from the English major. In addition, they stated many various answers about what factors influence the emersion of code-switching. The factors are the difficulty when conveying the meaning, to make the communication more inclusive to particular students/group/etc., to make the communication closer to particular students/group/etc., to convey meaning effectively, students' comprehension has not reached the goal of learning, to convey the meaning or comprehension contextually, to emphasize the meaning or comprehension, and to help EFL learners by bilingual.

Moreover, the participants stated code-switching affected English classrooms positively in transferring crosscultural understanding. They stated that code-switching eases students to understand more to the cultural topics/ materials given, the use of code-switching can improve students' comprehension to the topics/ materials on conceptual knowledge such as cultural activities, attitude and belief, and the use of code-switching is useful for EFL learners where they can match their English with local wisdom. In addition, the participants also stated that the use of code-switching can be a potential strategy to communicate in English classroom, and students can use this strategy 
when they have lack of vocabulary or English ability, and/ or they can use this code-switching to clarify the meaning they want to convey, especially in culture differences.

\section{Discussion}

Based on the findings above, it can be connected to the research questions or objectives. The first research question or objective is about what kinds of code-switching occurred in the English classroom. It showed among eight examples of code-switching, six of them are Inter-sentential Code Switching which is the second type of codeswitching used to describe a switch of language at sentence boundary or between the sentences.

Excerpt 1: Brain is an organ that serves as the center of the nervous system. Otak Adalah Pusat Sistem saraf (Brain is the center of the nervous system).

Because the participants taught young learners who lack vocabularies or difficult words, they used code-switching to convey the meaning.

Excerpt 2: Keep on learning. Kamu pasti bisa (You can do it).

The participants would like to emphasize the imperative sentence "Keep on learning" by using L1.

Another type of code-switching also emerged, Intra-sentential Code Switching which is the third type of codeswitching refers to the switch within a sentence.

Excerpt 3: Please tell me about the botol briefly. (botol is the bottle)

The participants likely used this code-switching unconsciously, because their L1 has quite a similar pattern so that they just change a particular word within the sentence. It is not like Inter-sentential Code Switching where the speaker used the code-switching consciously, because they wanted the students to understand more.

Unfortunately, another type of code-switching called Tag Switching has not found yet, but it may be because of the limitation of this study.

The second research question or objective relates to factors that influence the emersion of code-switching in the English Classroom. After concluding all the data, there are six factors, such as:

a) The desire to convey meaning effectively when dealing with the difficulty of conveying the meaning

b) The desire to make the communication more inclusive or closer to particular students/group/etc

c) The desire to improve students' comprehension when they have not reached the goal of learning

d) The desire to convey the meaning or comprehension contextually

e) The desire to emphasize the meaning or comprehension

f) The desire to help EFL learners by bilingual

The third research question or objective relates to how code-switching affecting English classrooms in transferring cross-culture understanding. There are

a) The use of code-switching eases students to understand more about cultural topics/ materials given, so the learning process becomes more effective.

b) The use of code-switching can improve students' comprehension of the topics/ materials on conceptual knowledge such as cultural activities, attitudes, and beliefs.

c) The use of code-switching is useful for EFL learners where they can match their English with local wisdom

The difference between the previous studies is the type of code-switching that found the most. In the previous study, Intra-sentential Code Switching is more frequently used because participants used many English terms in their workplace as a communication, whereas in this study, the participants more used Inter-sentential Code Switching because they want to help students to understand the class or improve their comprehension. In addition, this study tends to connect that code-switching is helpful for cross-cultural understanding.

\section{Conclusion}

Teaching L2 (English) through L2 (English) is what most people believed for over the years in any country. Nevertheless, the evidence that is pictured aside from the outcome of the students who learned the L2 through L2 is below the expectation. Therefore, there is a possible way to solve this problem, which is by translanguaging in the classroom. Translanguaging is the schedule performed by bilinguals of getting too diverse linguistic features or different models of what is portrayed as independent languages, in parliamentary strategy to maximize

Wedananta, K. A. (2020). Code-switching as a translanguaging to transfer cross-cultural understanding in English classroom: teachers' perception. International Journal of Linguistics, Literature and Culture, 6(1), 70-78. 
communicative potential and code switching is kind of translanguaging which it is the elective utilize by bilinguals of two or more languages within the same discussion or conversation.

This study was interested in identifying code-switching as a translanguaging to transfer cross-cultural understanding in the classroom. Most of the participants used Inter-sentential Code Switching, which is the second type of code-switching used to describe a switch of language at sentence boundary or between the sentences. They used the code-switching consciously, because of some factors, such as the desire to convey meaning effectively when dealing with difficulty of conveying the meaning, the desire to make the communication more inclusive or closer to particular students/group/etc., the desire to improve students' comprehension when they have not reached the goal of learning, the desire to convey the meaning or comprehension contextually, the desire to emphasize the meaning or comprehension, and the desire to help EFL learners by bilingual.

In addition, they believe that code-switching affects English classroom positively in transferring cross-cultural understanding, such as; code-switching eases students to understand more to cultural topics/ materials given, so learning process becomes more effective; code-switching can improve students' comprehension to the topics/ materials on conceptual knowledge such as cultural activities, attitude, and belief; and code-switching can be useful for EFL learners where they can match their English with local wisdom.

In conclusion, the code-switching here is not utilized to tell apart between two languages or the displacement of the languages but it is applied to mediate one another, to convey or emphasize the means, and to boost students' comprehension. Furthermore, code-switching as a translanguaging gives the support of TEFL in the classroom context. This study can be a consideration to use Code-switching to mediate each other especially when transferring cross-cultural understanding, to convey or emphasize the meaning, and to improve students' comprehension. However, the most important thing is how to determine the proportion of using Code Switching, so it can be a good reason to further researchers to figure out this issue. In addition, further researchers can dig deep into more issues on the relationship between Cross-cultural understandings and Code-Switching.

\section{Conflict of interest statement}

The author declared that he has no competing interests.

\section{Statement of authorship}

The author has a responsibility for the conception and design of the study. The author has approved the final article.

\section{Acknowledgments}

I am grateful to two anonymous reviewers for their valuable comments on the earlier version of this paper. 


\section{References}

Al Heeti, N., \& Al Abdely, A. A. (2016). Types and functions of code-switching in the English language used by Iraqi doctors in formal settings. International Journal of Advanced Research and Review, 1(8), 10-18.

Brown, H. D. (2000). Principles of language learning and teaching (Vol. 4). New York: Longman.

Celce-Murcia, M., Dörnyei, Z., \& Thurrell, S. (1995). Communicative competence: A pedagogically motivated model with content specifications. Issues in Applied linguistics, 6(2), 5-35.

Celce-Murcia, M., Dörnyei, Z., \& Thurrell, S. (1995). Communicative competence: A pedagogically motivated model with content specifications. Issues in Applied linguistics, 6(2), 5-35.

Dörnyei, Z. (1995). On the teachability of communication strategies. TESOL quarterly, 29(1), 55-85. https://doi.org/10.2307/3587805

Dörnyei, Z., \& Thurrell, S. (1991). Strategic competence and how to teach it.

Duranti, A. (Ed.). (2001). Key Terms in Language \& Culture (Vol. 11). Wiley-Blackwell.

García, O. (2009a). Bilingual education in the 21st century: A global perspective. Malden, MA, and Oxford, UK: Wiley/Blackwell.

García, O. (2009b). Emergent Bilinguals and TESOL: What's in a Name?. Tesol Quarterly, 43(2), 322-326.

Gumperz, J. J. (1982). Discourse strategies (Vol. 1). Cambridge University Press.

Huberman, M. (1987). Steps toward an integrated model of research utilization. Knowledge, 8(4), 586-611. https://doi.org/10.1177\%2F0164025987008004002

Hymes, D. (1967). Models of the interaction of language and social setting. Journal of social issues, 23(2), 8-28.

Maba, W. (2017). Teacher's perception on the implementation of the assessment process in 2013 curriculum. International Journal of Social Sciences and Humanities, 1(2), 1-9. https://doi.org/10.29332/ijssh.v1n2.26

Milroy, J. (1995). One speaker, two languages: Cross-disciplinary perspectives on code-switching. Cambridge University Press.

Nguyen, T. (2014). Code Switching: A sociolinguistic perspective. Anchor Academic Publishing (aap_verlag).

Oxford, R. (1990). Language learning strategies. New York, 3.

Oxford, R. L. (Ed.). (1996). Language learning strategies around the world: Cross-cultural perspectives (No. 13). Natl Foreign Lg Resource Ctr.

Poplack, S. (1980). Sometimes i'll start a sentence in spanish y termino en espanol: toward a typology of codeswitching1. Linguistics, 18(7-8), 581-618. https://doi.org/10.1515/ling.1980.18.7-8.581

Romaine, S. (2000). Language in society: An introduction to sociolinguistics. Oxford University Press.

Saville-Troike, M., \& Barto, K. (2016). Introducing second language acquisition. Cambridge University Press.

Shafi, S., Kazmi, S. H., \& Asif, R. (2020). Benefits of code-switching in language learning classroom at University of Education Lahore. International Research Journal of Management, IT and Social Sciences, 7(1), 227-234. https://doi.org/10.21744/irjmis.v7n1.842

Tarone, E., Yule, G., \& Yule, G. (1989). Focus on the language learner: Approaches to identifying and meeting the needs of second language learners (pp. 34-39). Oxford: Oxford University Press.

Yulianti, N.K.D. (2015). Cross Cultural Understanding In Language Learning. Retrieved from https://www.isidps.ac.id/artikel/cross-cultural-understanding-in-language-learning/

Wedananta, K. A. (2020). Code-switching as a translanguaging to transfer cross-cultural understanding in English classroom: teachers' perception. International Journal of Linguistics, Literature and Culture, 6(1), 70-78. 


\section{Biography of Author}

\begin{tabular}{|l|l|}
\hline \hline & Kadek Adyatna Wedananta, S.Pd., M.Pd received his Master's Degree in Postgraduate \\
Program of English Education at the Ganesha University of Education as known as \\
Universitas Pendidikan Ganesha Bali in 2014 and Bachelor's Degree in English \\
Education at Universitas Mahasaraswati Denpasar in 2011. Presently, He is an English \\
Lecturer at Undiknas University in Bali, He has a high motivation to build his students' \\
acquisition in applying English. Because of consistency in the English Education field \\
since 2011, he has experienced in dealing with English, linguistics, literature, and \\
pedagogy issues. He has worked on many studies that have been published on some \\
journals, one of them entitled Communication Strategies Used by Mathematics Science \\
Teachers to Communicate in English in Morning Sharing in SMP Nasional Plus \\
Jembatan Budaya: A Sociolinguistic Analysis that was published on e-Journal of \\
Postgraduate Program of English Education at Ganesha University of Education. His \\
research interests include English Education, Education, Applied Linguistics, Cultural \\
Studies, Sociolinguistics, and Communication Studies. \\
Email: adyatnawedananta@undiknas.ac.id
\end{tabular}

